CZASOPISMO INŻYNIERII LĄDOWEJ, ŚRODOWISKA I ARCHITEKTURY JOURNAL OF CIVIL ENGINEERING, ENVIRONMENT AND ARCHITECTURE JCEEA, t. XXXIII, z. 63 (3/16), lipiec-wrzesień 2016, s. 177-184

\author{
Piotr KONCA ${ }^{1}$ \\ Anna MAĆKOWIAK ${ }^{2}$ \\ Marcin KONIORCZYK ${ }^{3}$
}

\title{
TYNKI RENOWACYJNE JAKO OCHRONA MURÓW PRZED ZNISZCZENIEM WSKUTEK KRYSTALIZACJI SOLI
}

\begin{abstract}
W artykule przedstawiono badania dotyczące ochrony konstrukcji murowych przed zniszczeniem wskutek krystalizacji soli. Omówiono mechanizmy destrukcji wywołanej solą i warunki, w jakich do niej dochodzi. Przedstawiono rodzaje soli najczęściej występujących w warunkach rzeczywistych, a także zjawiska towarzyszące migracji roztworu i procesowi krystalizacji. Zdefiniowano ciśnienie krystalizacji, jako funkcję przesycenia roztworu oraz wielkości i kształtu porów, w których aktualnie następuje krystalizacja. Następnie określono klasy zasolenia konstrukcji murowych oraz układ warstw tynków renowacyjnych i ich wymiary zgodnie z zaleceniami niemieckiego instytutu WTA. Podkreślono, iż tynk renowacyjny to w rzeczywistości system składający się z obrzutki, warstwy podkładowej - magazynującej, tynku renowacyjnego - nawierzchniowego oraz ewentualnych szpachli i farb. Takie rozwiązanie ma za zadanie przesunąć strefę krystalizacji poza lico muru. W ostatniej części pracy przedstawiono wyniki badań tynku lekkiego cementowowapiennego na bazie perlitu ekspandowanego oraz popularnego przemysłowego tynku renowacyjnego pod kątem spełnienia wymagań normowych będących warunkiem wprowadzenia produktu na polski rynek. Przeanalizowano również spełnienie przez badane tynki kryteriów stawianych przez instrukcję instytutu WTA. Sprawdzono parametry świeżej mieszanki, przede wszystkim konsystencję, gęstość, zawartość porów powietrza. Dla stwardniałej mieszanki określono między innymi gęstość, porowatość, parametry wytrzymałościowe, paroprzepuszczalność, absorpcje wody i odporność na sole. Badania pokazują, iż ostatnie dwie cechy stanowią zasadniczą przeszkodę dla stosowania tynku lekkiego do zasolonych murów.
\end{abstract}

Słowa kluczowe: budynki zabytkowe, trwałość konstrukcji, transport i krystalizacja soli, tynki wielowarstwowe

\footnotetext{
${ }^{1}$ Piotr Konca, Politechnika Łódzka, Katedra Fizyki Budowli i Materiałów Budowlanych, Al. Politechniki 6, 90-924 Łódź; Piotr.konca@p.lodz.pl

2 Anna Maćkowiak, Politechnika Łódzka, Katedra Fizyki Budowli i Materiałów Budowlanych, Al. Politechniki 6, 90-924 Łódź; anna.mackowiak@p.lodz.pl

3 Autor do korespondencji / corresponding author: Marcin Koniorczyk, Politechnika Łódzka, Katedra Fizyki Budowli i Materiałów Budowlanych, Al. Politechniki 6, 90-924 Łódź; marcin.koniorczyk@p.lodz.pl
} 


\section{Wprowadzenie}

Mechanizm zniszczenia murów spowodowany obecnością różnych soli jest bardzo złożony. Zawilgocenie ścian może mieć źródła zewnętrzne i być wynikiem braku izolacji poziomej lub pionowej, uszkodzeniami pokrycia dachu lub obróbek blacharskich, deszczu zalewającego mur bezpośrednio, a także rozbryzgów od nawierzchni chodnika lub jedni podczas ruchu pojazdów. Mogą też występować wewnętrzne źródła zawilgocenia, takie jak przecieki instalacji wodno-kanalizacyjnej, brak wentylacji, czy nieodpowiedni sposób użytkowania pomieszczeń. Oprócz oczywistych negatywnych skutków występowania nadmiernej ilości wilgoci $\mathrm{w}$ materiałach budowlanych należy pamiętać, że szkodliwe substancje przemieszczają się wraz $\mathrm{z}$ nią. $\mathrm{W}$ przypadku roztworu zawierającego sole oznacza to, iż nie tylko dostaje się on wraz z wodą w głąb muru, ale w czasie odparowywania wilgoci do otoczenia sól krystalizuje w porach i na powierzchni przegrody.

Pomocne przy określeniu rodzaju, ilości i rozmieszczeni soli jest zidentyfikowanie jej źródła. Szczególnie w przypadku starszych materiałów budowlanych, zarówno cegieł jak zapraw, znaczna ilość związków łatwo tworzących sole wprowadzona była do materiałów już na etapie produkcji lub wbudowania.

Jednym ze sposobów przeciwdziałania zniszczeniu murów (Rys.1.) wskutek krystalizacji soli jest zastosowanie tynku renowacyjnego. Tynki jednowarstwowe stosuje się przy niskim lub średnim poziomie zasolenia. Najczęściej jednak jest to system przynajmniej trzech zapraw i ewentualnych szpachli do wykończenia powierzchni oraz farb. Wymagania te zostały sformalizowane przez

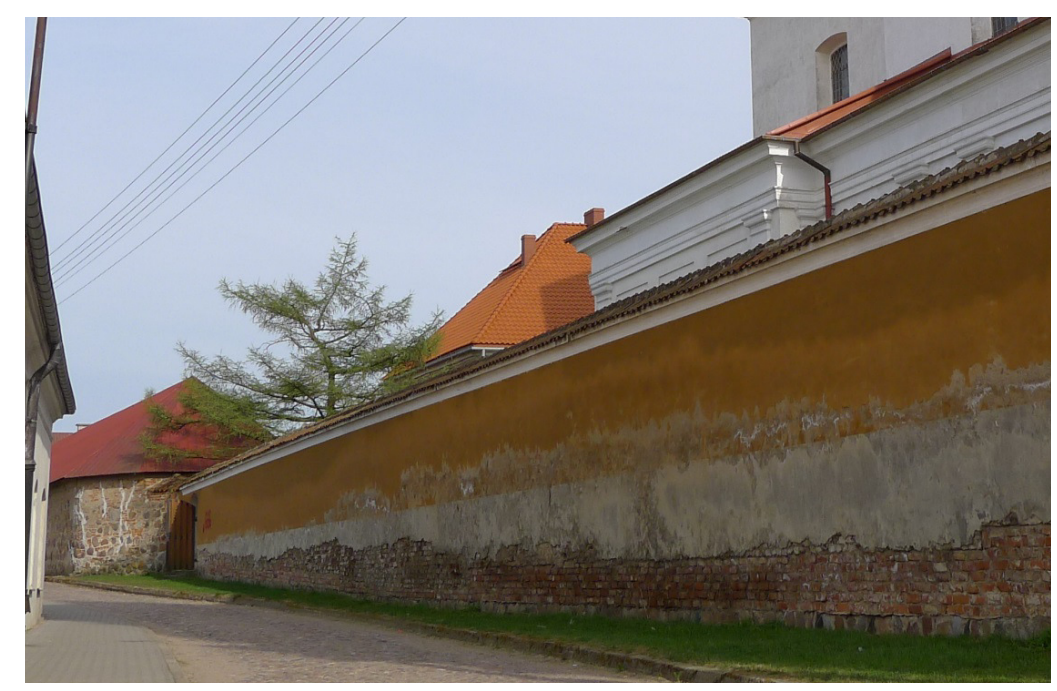

Rys. 1. Zniszcenie muru wskutek krystalizacji soli

Fig. 1. An example of salt crystallization induced damage of brick wall 
niemiecki instytut WTA (Wissenschaftlich-Technische Arbeitsgemeinschaft für Bauwerkserhaltung und Denkmalpflege) w instrukcji nr 2-9-04 Sanierputzsysteme [1]. Należy zauważyć, że polskie doświadczenia w tym obszarze również są znaczne i w dużej mierze pokrywają się ze wspomnianą instrukcją. Szereg wskazówek dotyczących prac przy obiektach zabytkowych znajdziemy w wielu publikacjach [2,3,4,5,6,8]. Aktualna norma europejska PN-EN 998-1:2012 Wymagania dotyczace zapraw do murów. Część 1: Zaprawa tynkarska wprowadza pojęcie tynku renowacyjnego, niestety $\mathrm{w}$ zasadzie nie precyzuje stawianych mu wymagań specjalnych [7].

W poniższym artykule po krótkim opisie mechanizmu zniszczenia materiałów budowlanych wskutek krystalizacji soli przedstawiono wstępne badania tynku lekkiego, jako tynku renowacyjnego. Próby zastąpienia gotowych tynków renowacyjnych tynkami lekkimi o składzie możliwie najbardziej zbliżonym do zapraw tradycyjnych są podejmowane ze względu na wymagania niektórych środowisk konserwatorskich.

\section{Krystalizacja soli w porowatych materiałach budowlanych}

Do soli najczęściej występujących w obiektach budowlanych należą siarczany, chlorki, azotany i węglany. Sole mogą występować w dwóch fazach: ciekłej, są to sole rozpuszczone w cieczy porowej oraz stałej, jako kryształy soli bądź związki zaadsorbowane na powierzchni szkieletu. Tylko sól rozpuszczona w fazie ciekłej może się przemieszczać. Sól może krystalizować w wyniku dwóch procesów. Pierwszym jest odparowanie wody, z którym mamy do czynienia podczas wysychania murów. Sól rozpuszczona przemieszcza się wraz $\mathrm{z}$ wodą, w kierunku powierzchni, skąd woda paruje. W konsekwencji stężenie soli $\mathrm{w}$ roztworze wzrasta $\mathrm{w}$ warstwie przypowierzchniowej, co prowadzi do przesycenia roztworu i krystalizacji soli. Niektóre sole mogą również krystalizować wskutek obniżenia temperatur, np. siarczan sodu lub magnezu, gdyż rozpuszczalność tych soli w wodzie zależy od temperatury.

Krystalizacji soli towarzyszy wzrost ciśnienia krystalizacyjnego wywieranego na ściany szkieletu. Szczególnie duże wartości ciśnienia odnotowuje się dla siarczanu sodu, z którego powstaje dekahydrat siarczanu sodu zwany mirabilitem. Objętość molowa mirabilitu jest 4.5 krotnie większa niż objętość siarczanu sodu. Steiger $[9,10]$ wyprowadził wzór ujmujący zależność ciśnienia krystalizacji od stopnia przesycenia, zdefiniowanego przy pomocy parametrów termodynamicznych charakteryzujących objętość roztworu:

$$
\Delta p=\frac{R T}{V_{m}} \ln \left(\frac{a}{a_{\infty}}\right)-\bar{\gamma}_{c l} \frac{d A}{d V}
$$

gdzie: $V_{m}$ jest objętością molową, $R$ jest stałą gazową, $T$ jest temperaturą bezwzględną, $a$ jest aktywnością jonów w roztworze wypełniającym pory o danym 
promieniu, $a_{\infty}$ jest iloczynem rozpuszczalności w objętości roztworu, $A$ jest polem powierzchni a $V$ jest objętością poru. Powyższy wzór pozwala na uwzględnienie wpływu wielkości i kształtu porów na wartość ciśnienia krystalizacji. Powyższą zależność graficznie przedstawiono na Rys. 4. Sól krystalizuje począwszy od porów największych, następnie wraz ze wzrostem stopnia przesycenia roztworu kryształy soli zajmują coraz mniejsze pory.

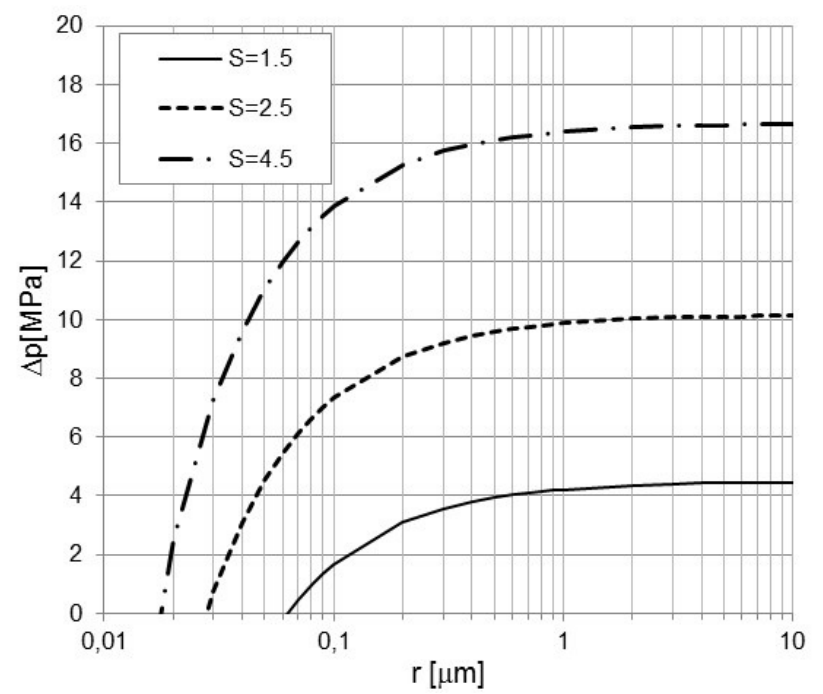

Rys. 2. Wartość ciśnienia krystalizacji obliczona dla trzech wartości stopnia przesycenia roztworu w funkcji średnicy porów

Fig. 2. Crystallization pressure as a function of solution supersaturation ratio and the size and shape of pores

\section{Tynki renowacyjne}

Instrukcja WTA definiuje, podstawową wytyczną do wyboru ilości składników (Tab. 2) systemu renowacyjnego jako stopień zasolenia (Tab. 1.). Zasada działania tynków renowacyjnych opiera się na zjawiskach dyfuzji pary wodnej i migracji roztworu soli do porowatego ośrodka. Sól krystalizuje w strefie odparowania wilgoci, uwidaczniając się na powierzchni ścian w postaci charaktery-

Tablica 1. Stopnie zasolenia wg instrukcji WTA nr 2-9-04

Table 1. Degree of salinity according to the WTA instruction No 2-9-04

\begin{tabular}{|c|c|c|c|}
\hline \multirow{2}{*}{$\begin{array}{c}\text { Rodzaj } \\
\text { soli }\end{array}$} & Stopień zasolenia \\
\cline { 2 - 4 } & Niski & Średni & Wysoki \\
\hline Chlorki & $<0,2$ & $0,2-0,5$ & $>0,5$ \\
\hline Siarczany & $<0,5$ & $0,5-1,5$ & $>1,5$ \\
\hline Azotany & $<0,1$ & $0,1-0,3$ & $>0,3$ \\
\hline
\end{tabular}


Tablica 2. Elementy systemu tynku renowacyjnego wg instrukcji WTA nr 2-9-04

Table 2. Components of renovation plaster system according the WTA instruction No 2-9-04

\begin{tabular}{|c|c|c|}
\hline Stopień zasolenia & Układ warstw & $\begin{array}{c}\text { Grubość } \\
{[\mathrm{mm}]}\end{array}$ \\
\hline \multirow{2}{*}{ Niski } & Obrzutka & $\leq 5$ \\
& Tynk renowacyjny & $\geq 20$ \\
\hline \multirow{5}{*}{ Średni do wysokiego } & Obrzutka & $\leq 5$ \\
& Tynk renowacyjny & $10-20$ \\
& Tynk renowacyjny & $10-20$ \\
\cline { 2 - 3 } & Obrzutka & $\leq 5$ \\
& Tynk podkładowy & $10-20$ \\
& Tynk renowacyjny & $10-20$ \\
\hline
\end{tabular}

stycznych białych, lekko wypukłych śladów. W strefie przypowierzchniowej sól krystalizuje w porach materiałów, zwiększając znacznie swoją objętość. W trakcie tego procesu na ścianki porów oddziałują siły związane z tzw. ciśnieniem krystalizacji. W efekcie strefa przypowierzchniowa materiału ulega destrukcji obejmującej w pierwszej fazie pojawienie się spękań, miejscowe murszenie i odspajanie. Dochodzi do zniszczenia najpierw wyprawy tynkarskiej, spoin a następnie cegły, aż do całkowitej utraty przez nią lica. Strefa krystalizacji przesuwa się w ten sposób w głąb muru. Dodatkowo występująca w porach sól uszczelnia materiał utrudniając wysychanie muru.

Tynk renowacyjny ma za zadanie przesunąć strefę odparowania poza lico muru. Jego struktura wewnętrzna powinna pozwalać na bezpieczne magazynowanie soli, nie dopuszczając do wykwitów na powierzchni tynku. Jednocześnie musi on zabezpieczać mur przed wnikaniem wody przez powierzchnię przegrody uniemożliwiając wtórny transportu soli w głąb muru. Konieczne jest to również ze względu na wysychanie samej konstrukcji. Stosowanie rozwiązań systemowych jest skuteczniejsze, niż zastosowanie tynków jednowarstwowych.

System tynków renowacyjnych obejmuje podstawowe elementy:

- obrzutkę;

- tynk podkładowy;

- tynk nawierzchniowy;

- ewentualnie szpachle wygładzające lub strukturalne i farby.

\subsection{Badania laboratoryjne}

Do wprowadzenia tynku renowacyjnego $(\mathrm{R})$ na rynek polski wystarczy deklaracja zgodności wyrobu z normą. Jedyną normą, która wymienia i stawia wymagania takim tynkom jest EN 998-1.

Tynk renowacyjny jest tynkiem porowatym, mającym zapewnić dużo objętości dla powstających kryształów soli, więc wydawać by się mogło, że zastosowanie tynku lekkiego (LW) może być dobrym rozwiązaniem. W artykule 
Tablica 3. Zestawienie wyników badań laboratoryjnych i wymagań normowych

Table 3. Experimental results and requirements of the standards

\begin{tabular}{|c|c|c|c|}
\hline $\begin{array}{l}\text { Parametr i wymaga- } \\
\text { nia według normy } \\
\text { PN-EN 998-1 }\end{array}$ & $\begin{array}{c}\text { Wymagania PN-EN } \\
998-1\end{array}$ & Tynk LW & Tynk R \\
\hline $\begin{array}{c}\text { Czas zachowania } \\
\text { własności roboczych } \\
{[\mathrm{min}]}\end{array}$ & $\begin{array}{l}\text { LW Deklaracja } \\
\text { R Deklaracja }\end{array}$ & 30 & 60 \\
\hline $\begin{array}{c}\text { Gęstość Stwardniałej } \\
\text { zaprawy }\left[\mathrm{kg} / \mathrm{m}^{3}\right]\end{array}$ & $\begin{array}{c}\mathrm{LW}<1300 \mathrm{~kg} / \mathrm{m}^{3} \\
\mathrm{R} \text { Deklaracja }\end{array}$ & 990 & 1390 \\
\hline $\begin{array}{l}\text { Wytrzymałość na } \\
\text { ściskanie }\left[\mathrm{N} / \mathrm{mm}^{2}\right]\end{array}$ & $\begin{array}{l}\mathrm{LW} \text { od } 0,4 \text { do } 7,5 \\
\mathrm{R} \text { od } 1,5 \text { do } 5,0\end{array}$ & 3,4 & 2,8 \\
\hline $\begin{array}{c}\text { Przyczepność } \\
{\left[\mathrm{N} / \mathrm{mm}^{2}\right]}\end{array}$ & $\begin{array}{l}\text { LW Deklaracja } \\
\text { R Deklaracja }\end{array}$ & 0,3 & 0,1 \\
\hline $\begin{array}{l}\text { Absorpcja wody } \\
\text { przez podciąganie } \\
\text { kapilarne }\end{array}$ & $\begin{array}{c}\mathrm{LW} \text { od W0 do W3 } \\
{\left[\mathrm{kg} /\left(\mathrm{m}^{2} \cdot \min ^{0,5}\right)\right]} \\
\mathrm{R} \geq 0.3\left[\mathrm{~kg} / \mathrm{m}^{2}\right]\end{array}$ & $\begin{array}{c}0,75(\mathrm{~W} 0) \\
23,2\end{array}$ & $\begin{array}{c}0,04(\mathrm{~W} 3) \\
1,76\end{array}$ \\
\hline $\begin{array}{c}\text { Głębokość wnikania } \\
\text { wody }[\mathrm{mm}]\end{array}$ & $\begin{array}{l}\text { LW brak wymagań, } \\
\text { R } \leq 5\end{array}$ & 47,0 & 3,3 \\
\hline $\begin{array}{l}\text { Współczynnik prze- } \\
\text { puszczalności pary } \\
\text { wodnej }\end{array}$ & $\begin{array}{l}\text { LW Deklaracja } \\
\quad \mathrm{R} \leq 15\end{array}$ & 7,3 & 6,6 \\
\hline
\end{tabular}

przedstawiono (Tab. 3,4) wyniki badań tynku renowacyjnego dostępnego na rynku i tynku lekkiego cementowo-wapiennego na bazie perlitu ekspandowanego wykonanego w laboratorium.

Jedyną cechą tynku lekkiego, która powoduje brak możliwości zadeklarowania spełnienia wymagań takich, jak dla tynku renowacyjnego w tym przypadku jest głębokość wnikania wody. Tynk lekki charakteryzuje się bardzo dużą absorpcją wody przy bardzo dużej głębokości jej wnikania (dla tynku LW brak wymagań co do tej cechy), natomiast od tynku renowacyjnego wymaga się odpowiednio wysoką absorpcję (powyżej $0,3 \mathrm{~kg} / \mathrm{m}^{2}$ ), przy jednocześnie niskiej głębokości wnikania wody (poniżej $5 \mathrm{~mm}$ ).

\section{Wnioski}

Podsumowując, zwykły tynk lekki nie spełnił wymagań normy dotyczących tynku renowacyjnego w jednym punkcie. Natomiast tynk renowacyjny, który spełnia wymagania normy PN-EN 998-1 i może być wprowadzony do obrotu na rynku budowlanym, może nie spełniać wszystkich wymagań instrukcji WTA. $\mathrm{W}$ instrukcji postawiono wysokie wymagania dotyczące tynków renowacyjnych, których realizacja może zapewnić korzystne działanie. Jednocześnie nie jest to dokument, na podstawie którego można wprowadzać wyroby budowlane do obrotu i stosowania na rynku europejskim. 
Tablica 4. Zestawienie wymagań zgodnie z WTA-2-9-04 i wyników badań eksperymentalnych

Table 4. Requirements set by the WTA instruction No 2-9-04 and experimental results

\begin{tabular}{|c|c|c|c|}
\hline Parametr & Wymogi & Tynk LW & Tynk R \\
\hline $\begin{array}{l}\text { Konsystencja } \\
\text { pływ) }[\mathrm{mm}]\end{array}$ & $170 \pm 5$ & 170 & 171 \\
\hline $\begin{array}{l}\text { Gęstość świeżej za- } \\
\text { prawy }\left[\mathrm{kg} / \mathrm{m}^{3}\right]\end{array}$ & Deklaracja & 1387 & 1447 \\
\hline $\begin{array}{l}\text { Zawartość porów po- } \\
\text { wietrza w świeżej za- } \\
\text { prawie [\%] }\end{array}$ & $>25 \%$ & 26 & 35 \\
\hline Porowatość [\%] & $>40 \%$ & 42 & 27 \\
\hline $\begin{array}{l}\text { Wytrzymałość na zgi- } \\
\text { nanie }\end{array}$ & Deklaracja & 1,2 & 1,1 \\
\hline $\begin{array}{l}\text { Wytrzymałość na ści- } \\
\text { skanie }\end{array}$ & $1.5<\mathrm{W}<5$ & 3,4 & 2,8 \\
\hline $\begin{array}{l}\text { Stosunek wytrzymało- } \\
\text { ści na ściskanie do } \\
\text { wytrzymałości na zgi- } \\
\text { nanie }\end{array}$ & $<3$ & 2,8 & 2,5 \\
\hline $\begin{array}{l}\text { Absorpcja wody spo- } \\
\text { wodowana podciąga- } \\
\text { niem kapilarnym w } \\
\text { ciągu } 24 \mathrm{~h}\left[\mathrm{~kg} / \mathrm{m}^{2}\right]\end{array}$ & $>0.3$ & 23,2 & 1,76 \\
\hline $\begin{array}{ll}\text { Głębokość } & \text { wnikania } \\
\text { wody }[\mathrm{mm}] & \\
\end{array}$ & $<5$ & 47 & 3,3 \\
\hline Odporność na sole & Odporny & Brak odporności & Odporny \\
\hline $\begin{array}{lr}\text { Współczynnik } & \text { prze- } \\
\text { puszczalności } & \text { pary } \\
\text { wodnej } & \end{array}$ & $<12$ & 7,3 & 6,6 \\
\hline
\end{tabular}

\section{Literatura}

[1] WTA Merkblatt 2-9-04 Sanierputzsysteme, Monachium 2004.

[2] Domasłowski W., red., Zabytki kamienne i metalowe, ich niszczenie i konserwacja profilaktyczna, Toruń 2011.

[3] Frössel F., Osuszanie murów i renowacja piwnic, Warszawa 2007.

[4] Praca zbiorowa pod kier. P. Klemm, Budownictwo ogólne, Tom 2, Fizyka budowli, Warszawa 2005.

[5] H. Stankiewicz, Zabezpieczenie budowli przed wilgocią, wodą gruntową i korozją, Warszawa 1984.

[6] M. Rokiel, Tynki renowacyjne w świetle normy „PN-EN 998-1 Wymagania dotyczące zapraw do murów. Część 1. Zaprawa tynkarska” oraz instrukcji „WTA nr 2-904 Sanierputzsysteme”, Inżynier budownictwa 9/2012. 
[7] PN-EN 998-1:2012, Wymagania dotyczące zapraw do murów. Część 1: Zaprawa tynkarska.

[8] Koniorczyk, M., Gawin, D., Modelling of salt crystallization in building materials with microstructure -Poromechanical approach, Construction and Building Materials, 2012, 860-873.

[9] Steiger, M., Crystal growth in porous materials-I: the crystallization pressure of large crystals. Journal of Crystal Growth 282, 2005, 455-469.

[10] Steiger, M., Crystal growth in porous materials-II: Influence of crystal size on the crystallization pressure. Journal of Crystal Growth 282, 2005, 470-481.

\section{RENOVATION PLASTER AS A PROTECTION AGAINST SALT CRYSTALLIZATION INDUCED DAMAGE}

\section{S u m m a r y}

We present the research aims at the better protection of brick wall against salt crystallization induced damage. Damage mechanisms and conditions enable destruction were elaborated. We present salts, which are most destructive in real constructions. The formula defining crystallization pressure as a function of solution supersaturation ratio and the size and shape of pores, where the crystallization proceeds, is defined. Classes of salt content and the dimensions of composite layers due to German WTA Institute is given. It is also stressed that renovation plaster is actually a whole system containing rendering, ground plaster coat - as salt storage, renovation plaster - external protective layer and additional putties and paints. The paper is finished with the results of experimental research on the comparison of light lime-cement plaster with expanded perlite and popular commercial-made renovation plaster. Whole range of research of fresh and hardened mortars has been performed. For fresh mortar especially the consistence, density and content of air pores has been evaluated. The hardened product has been examined due to set density, porosity, compressive and bending strength, diffusion, water absorption coefficient and resistance to salts damage. Two last properties doesn't allow to apply light plasters for salt attacked walls.

Keywords: historical buildings, durability of constructions, salt transport and crystallization, composite plasters

DOI:10.7862/rb.2016.199

Przestano do redakcji: 24.04.2016 $r$.

Przyjęto do druku: $30.11 .2016 r$. 